\title{
Heterodimers of Heterometallic Rings
}

DOI:

10.1039/C6DT01941B

\section{Document Version}

Accepted author manuscript

Link to publication record in Manchester Research Explorer

\section{Citation for published version (APA):}

Timco, G., Mcinnes, E., Pritchard, R., Tuna, F., \& Winpenny et al, R. (2016). Heterodimers of Heterometallic Rings. Dalton Transactions, 45, 16610-16615. https://doi.org/10.1039/C6DT01941B

\section{Published in:}

Dalton Transactions

\section{Citing this paper}

Please note that where the full-text provided on Manchester Research Explorer is the Author Accepted Manuscript or Proof version this may differ from the final Published version. If citing, it is advised that you check and use the publisher's definitive version.

\section{General rights}

Copyright and moral rights for the publications made accessible in the Research Explorer are retained by the authors and/or other copyright owners and it is a condition of accessing publications that users recognise and abide by the legal requirements associated with these rights.

\section{Takedown policy}

If you believe that this document breaches copyright please refer to the University of Manchester's Takedown Procedures [http://man.ac.uk/04Y6Bo] or contact uml.scholarlycommunications@manchester.ac.uk providing relevant details, so we can investigate your claim.

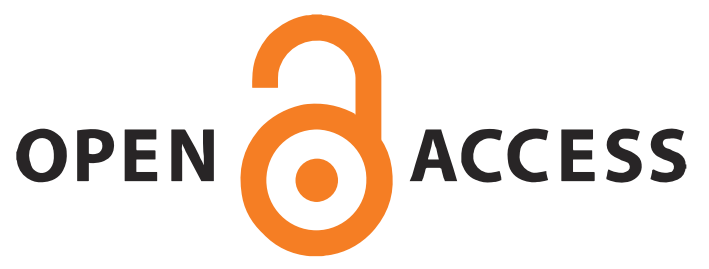




\title{
Heterodimers of Heterometallic Rings
}

\author{
Grigore Timco, ${ }^{\text {a }}$ Simone Marocchi, ${ }^{\text {bcc }}$ Elena Garlatti, ${ }^{\mathrm{d}}$ Claire Barker, ${ }^{\mathrm{a}}$ Morten Albring, ${ }^{\mathrm{a}}$ Valerio Bellini, \\ Franca Manghi, ${ }^{\text {b,c }}$ Eric J. L. McInnes, ${ }^{a}$ Robin G. Pritchard, ${ }^{a}$ Floriana Tuna, ${ }^{a}$ Wolfgang Wernsdorfer, ${ }^{\mathrm{e}}$ \\ Giulia Lorusso, ${ }^{\mathrm{b}, \mathrm{c}, \mathrm{s}}$ Giuseppe Amoretti, ${ }^{\mathrm{d}}$ Stefano Carretta, ${ }^{\mathrm{d}}$ Marco Affronte ${ }^{\mathrm{b}, \mathrm{c}_{*}}$ and Richard E. P. \\ Winpenny ${ }^{\mathrm{a}}$ *
}

\author{
Received (in XXX, XXX) Xth XXXXXXXXX 200X, Accepted Xth XXXXXXXXX 200X \\ First published on the web Xth $X X X X X X X X X 200 X$ \\ DOI: 10.1039/b000000x
}

\begin{abstract}
Nine new complexes are reported involving linked heterometallic 10 rings; one ring is designed as a ligand for the second, and the compounds produced can be regarded as molecular prototypes for implementing quantum gates featuring two subtly different qubits.
\end{abstract}

We have been exploring the idea that heterometallic rings can be 15 used as qubits for quantum computing, ${ }^{1}$ and have developed two families of heterometallic rings - one that can act as a Lewis base, ${ }^{2}$ and hence be linked via simple Lewis acids such a single copper(II) site, and a second family that contains a single displaceable ligand and hence can act as a Lewis acid, ${ }^{3}$ and which 20 can be linked by reaction with simple di-imines. ${ }^{4}$ Here we report the reaction between these two families of heterometallic rings. Other groups are studying other molecular routes towards quantum computing, including organic radicals, ${ }^{5}$ other polymetallic complexes ${ }^{6}$ and simple coordination compounds. ${ }^{7}$

${ }_{25}$ The first family of heterometallic rings, ${ }^{8}$ which are green in colour, has the general formula $\left[\mathrm{NEt}_{2} \mathrm{H}_{2}\right]\left[\mathrm{Cr}_{7} \mathrm{MF}_{8}\left(\mathrm{O}_{2} \mathrm{C}^{\mathrm{t}} \mathrm{Bu}\right)_{16}\right]$; here we discuss $\mathrm{M}=\mathrm{Ni}, \mathrm{Mn}$ or $\mathrm{Zn}$. The metal sites form an octagon with each edge bridged by a fluoride and two pivalate ligands. Reaction of these compounds with iso-nicotinic acid 30 allows the synthesis of rings that are substituted with a single iso-nicotinate: $\left[\mathrm{NEt}_{2} \mathrm{H}_{2}\right]\left[\mathrm{Cr}_{7} \mathrm{MF}_{8}\left(\mathrm{O}_{2} \mathrm{C}^{\mathrm{t}} \mathrm{Bu}\right)_{15}\left(\mathrm{O}_{2} \mathrm{C}-\mathrm{py}\right)\right] \mathrm{M}=\mathrm{Ni}$, 1; $\mathrm{Mn}, 2$; $\mathrm{Zn}, 3$. The relative rates of reaction of chromium(III) and the divalent metal $^{9}$ means that the incoming nicotinate group must bind to an edge of the cage 35 that contains the divalent metal.

The second family or rings, which are purple in colour, ${ }^{10}$ has the general formula $\left[\mathrm{Cr}_{7} \mathrm{M}^{\prime} \mathrm{F}_{3}(\mathrm{Etglu})\left(\mathrm{O}_{2} \mathrm{C} t \mathrm{Bu}\right)_{15}\left(\mathrm{OEt}_{2}\right)\right]$, $\mathrm{M}^{\prime}=\mathrm{Ni}, 4 ; \mathrm{Mn}, \mathbf{5} ; \mathrm{Zn}, \mathbf{6} ; \mathrm{H}_{5}$ EtGlu $=N$-ethyl- $D$-glucamine. This family is made from reaction of $\mathrm{CrF}_{3} \cdot \mathrm{xH}_{2} \mathrm{O}$ with pivalic 40 acid in the presence of $\mathrm{H}_{5}$ EtGlu and a complex of the relevant divalent metal. Again, the eight metals form an octagon with the exterior of the octagon bridged by pivalate; in the centre of the ring is the penta-deprotonated $\mathrm{EtGlu}^{5-}$ ligand, with each alkoxide bridged two metal sites. The key feature of 45 complexes $\mathbf{4}-\mathbf{6}$ is the presence of a displaceable molecule (water as made $)^{10}$ bound to the divalent metal site.

\section{Results and discussion}

If a functionalised green ring is mixed with a purple ring, 50 we obtain dimers of formula: $\left[\mathrm{NEt}_{2} \mathrm{H}_{2}\right]\left[\mathrm{Cr}_{7} \mathrm{MF}_{8}\left(\mathrm{O}_{2} \mathrm{C}^{\mathrm{t}} \mathrm{Bu}\right)_{15}\left(\mathrm{O}_{2} \mathrm{C}-\mathrm{py}\right)\right.$

$\left.\mathrm{Cr}_{7} \mathrm{M}^{\prime} \mathrm{F}_{3}(\mathrm{Etglu})\left(\mathrm{O}_{2} \mathrm{C} t \mathrm{Bu}\right)_{15}\right]$; we have made all nine members of the family, varying both $M$ and $M^{\prime}\left(M=M^{\prime}=N i\right.$ 7); the synthesis of the other compounds is described in the ${ }_{55}$ supplementary information. We can thus make a family of metal assemblies containing sixteen metals, with up to three different identities, knowing precisely where the different metals are positioned. The nine compounds are isostructural with the individual rings unchanged from the reactants. The 60 only change is that in place of the diethylether group in complexes 4-6, the divalent site is bound to a pyridine from iso-nicotinate. The structure of 7 is shown in Figure 1; the large molecules pack inefficiently in the lattice and there are large voids in the structure which we assume are filled with ${ }_{65}$ solvent however these are so disordered they could not be located.

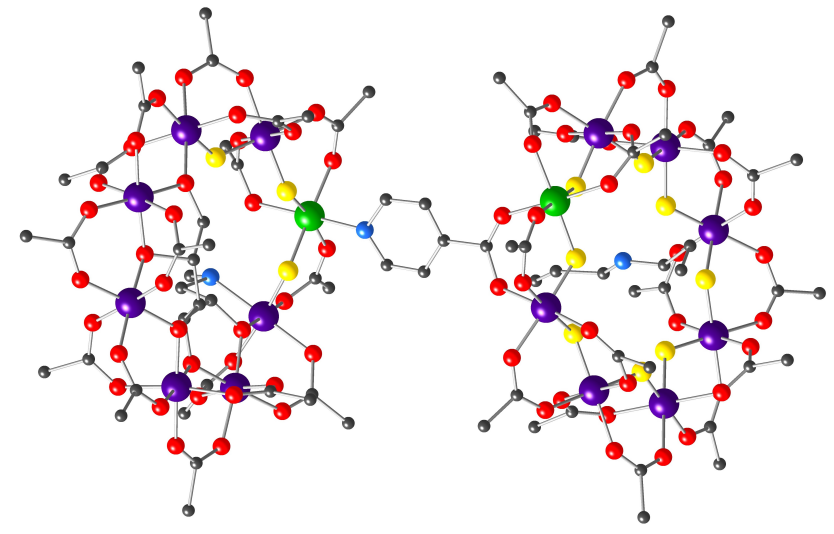

Figure 1. The structure of complex 7 in the crystal; the "green" ring is shown to the right of the picture. Colours: $\mathrm{Cr}$, purple; Ni, green; F, 70 yellow; $\mathrm{O}$, red; $\mathrm{N}$, light blue; $\mathrm{C}$, black. $\mathrm{H}$ atoms and methyl groups removed for clarity.

The family of linked cages creates the opportunity to study the exchange interaction in these iso-structural complexes. The $\left\{\mathrm{Cr}_{7} \mathrm{Ni}\right\}$ compounds $\mathbf{1}$ and $\mathbf{4}$ are the compounds regarded 75 as possible qubits for quantum information processing as they have $S=1 / 2$ spin ground states. Therefore here we report studies of compound 7; and show by a variety of methods that there is a weak but measurable interaction between the two rings in this molecular ensemble. As the structures of $\mathbf{1}$ and $\mathbf{4}$ 80 are essentially replicated in 7 the only new parameters involved in fitting data involve the exchange interactions between the rings.

Magnetic susceptibility data of 7 between $2 \mathrm{~K}$ and $300 \mathrm{~K}$ practically coincide with the sum of the susceptibilities of the ${ }_{85}$ two component rings (Figure S1). However, very low- 
temperature magnetization $\mathrm{M}(\mathrm{H})$ curves measured with a microSQUID clearly show a plateau around zero magnetic field $H$. This demonstrates the presence of an effective antiferromagnetic coupling between the two rings in their $S$ ${ }_{5}=1 / 2$ ground states, leading to a ground state singlet (Figure 2). Zero-field specific heat (Figure 3) corroborates this finding by showing an upturn below $1 \mathrm{~K}$, corresponding to an incipient Schottky anomaly due to the singlet-triplet. Conversely, Figure 3 shows that in a sizeable magnetic field 10 the Schottky anomaly follows the behavior of isolated rings.

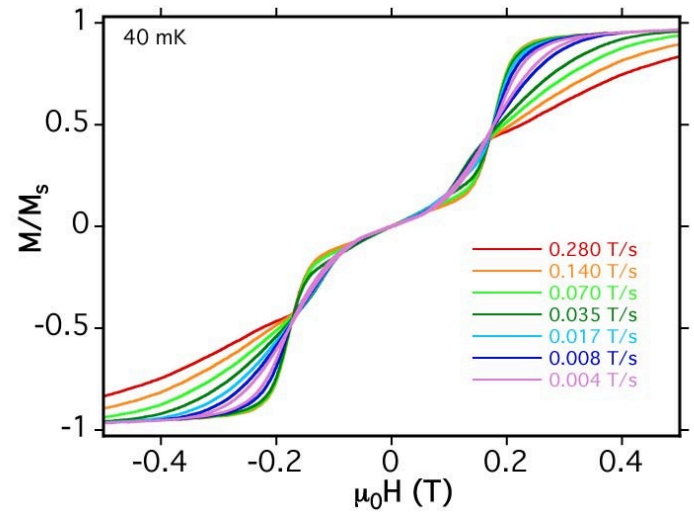

Figure 2 Low temperature magnetization of 7. The plateau at zero field is due to antiferromagnetic coupling between the rings.

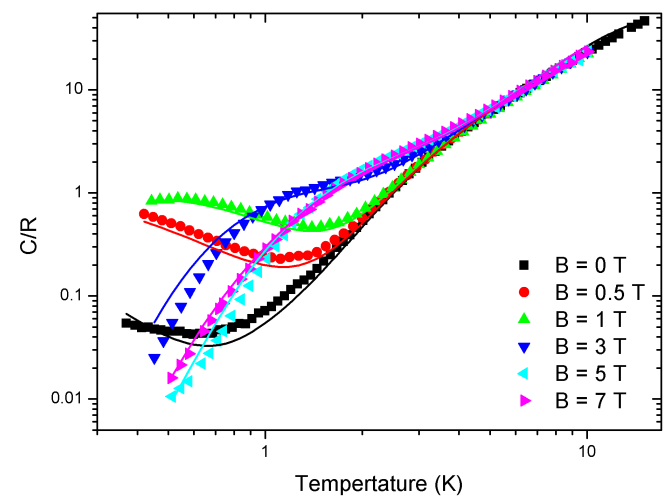

Figure 3 Temperature and magnetic field dependence of molar specific 15 heat $C$ (in gas constant $R=8.314 \mathrm{~J} / \mathrm{mol} \mathrm{K}$ units) for 7 (markers). (Solid lines) simulations of specific heat for 7 , calculated as described in the text.

EPR spectroscopy is very sensitive to weak exchange interactions. $^{4}$ In particular, for 7 the continuous wave EPR 20 spectra at X-, Q- and W-band show that the two $S=1 / 2$ centres are magnetically interacting. The resulting spectra (Figure 4) are not a clearly resolved triplet, as we have previously found for exchange-coupled heterometallic rings. ${ }^{4 b}$ However, they are not interpretable as simply due to the sum ${ }_{25}$ of the spectra of $\mathbf{1}$ and $\mathbf{4}$. It is noticeable that the weak feature at ca. $2800 \mathrm{mT}$ is much broader in the experimental spectrum than in the simulation.

These findings can be understood by describing the supramolecular dimer with a microscopic Hamiltonian [1] $H$ 30 which is the sum of those of single purple and green rings $\left(H_{p}\right.$ and $H_{g}$ ), and of an exchange term between the two rings:
[1]

$$
\begin{aligned}
H=H_{p} & +H_{g}+J_{\mathrm{Ni}(\mathrm{p})-\mathrm{Cr}(\mathrm{g})} \boldsymbol{s}_{\mathrm{Ni}(\mathrm{p})} \cdot \boldsymbol{s}_{\mathrm{Cr}(\mathrm{g})} \\
& +J_{\mathrm{Ni}(\mathrm{p})-\mathrm{Ni}(\mathrm{g})} \boldsymbol{s}_{\mathrm{Ni}(\mathrm{p})} \cdot \boldsymbol{s}_{\mathrm{Ni}(\mathrm{g})}
\end{aligned}
$$

where the Hamiltonians describing single rings are 35

$$
\begin{aligned}
& {[2] H_{p, g}=\sum_{i=1}^{6} J \cdot \boldsymbol{s}_{i} \cdot \boldsymbol{s}_{i+1}+J^{\prime}\left(\boldsymbol{s}_{1} \cdot \boldsymbol{s}_{N i}+\boldsymbol{s}_{7} \cdot \boldsymbol{s}_{N i}\right)+} \\
& \sum_{i} d_{i} s_{z_{i}}^{2}+\sum_{i} e_{i}\left(s_{x_{i}}^{2}-s_{y_{i}}^{2}\right)+\mu_{B} \boldsymbol{B} \cdot \sum_{i} \boldsymbol{g}_{\boldsymbol{i}} \cdot \boldsymbol{s}_{\boldsymbol{i}} .
\end{aligned}
$$

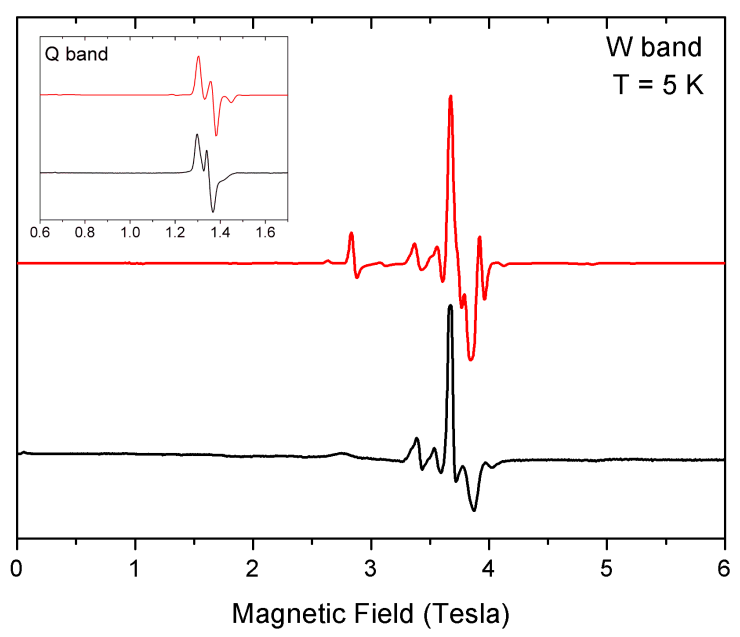

Figure 4. W-band $(93.95948 \mathrm{GHz})$ EPR spectrum of 7 (black) with 40 simulation (red). The spectra were measured on powder samples at 5 $\mathrm{K}$; the simulations are based on the parameters discussed in the text. The inset reports the measured and simulated Q-band $(34.1585 \mathrm{GHz})$ spectrum.

${ }_{45}$ The parameters $J, J^{\prime}, d_{i}, e_{i}$ and the $g$ tensors for both single rings have been determined by thermodynamic and spectroscopic measurements ${ }^{3,8}$ and are given in Supplementary Table 1. These parameters were fixed in modelling the data of 7 .

50 To understand the coupling between the rings in 7 it is important to first realise that the exchange involves three metal centres (Figure 5). The Ni site in the purple ring is coupled to two metal centres in the green ring; one of these metal centres is a $\mathrm{Cr}$ and the other a $\mathrm{Ni}$. In the $S=1 / 2$ ground ${ }_{55}$ doublet of each ring, the $\mathrm{Ni}$ spin is opposite to the total spin $S,{ }^{10}$ whereas the $\mathrm{Cr}$ spin involved in inter-ring interaction is parallel to $S$. Hence, the most straightforward way to explain the effective antiferromagnetic coupling found by microSQUID measurements is to assume that between there ${ }_{60}$ rings there is a ferromagnetic Ni-Cr interaction $\left(\mathrm{N}_{\mathrm{Ni}(\mathrm{p})-\mathrm{Cr}(\mathrm{g})}<\right.$ $0)$ and an antiferromagnetic $\mathrm{Ni}-\mathrm{Ni}$ coupling $\left(\mathrm{J}_{\mathrm{Ni}(\mathrm{p})-\mathrm{Ni}(\mathrm{g})}>\right.$ 0 , see Fig. 5). In particular, we find that assuming $J_{\mathrm{Ni}(\mathrm{p})-\mathrm{Ni}(\mathrm{g})}=-J_{\mathrm{Ni}(\mathrm{p})-\mathrm{Cr}(\mathrm{g})}=0.17 \mathrm{~K}$ allows us to satisfactorily interpret specific heat and EPR data (lines in Figures 3 and 4).

${ }_{65}$ In addition, this model is consistent with the results of $a b$ initio density functional theory (DFT) calculations (see below). Transitions involving excited states of the single rings (with $S>1 / 2$ ) contribute to the W-band EPR spectrum. In particular, the observed transition at about $2.8 \mathrm{~T}$ involves 70 the $S=3 / 2$ multiplets. Transitions involving excited states could be at the origin of the observed broadening of the 
corresponding line.

The magnetic-field dependence of the low-lying energy levels of 7 resulting from this model is reported in Figure 6 for $\mathbf{B}$ ${ }_{5}$ perpendicular to the rings. The position of the singlet-triplet

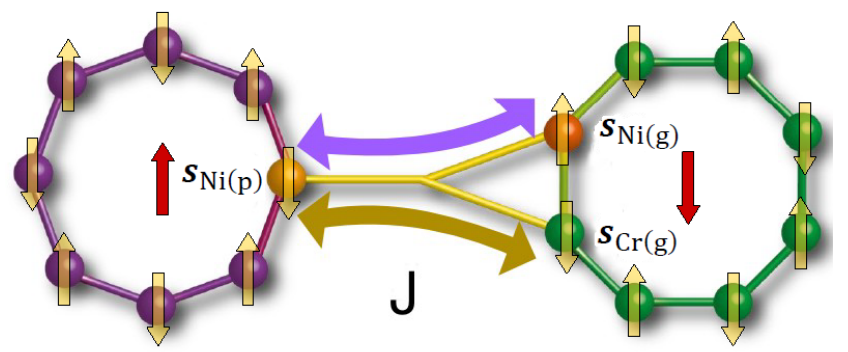

Figure 5 Sketch of the two possible magnetic interaction channels across the isonicotinate bridge. Yellows arrows indicate local spins, while red arrows represent the total spin of the rings.

crossing is consistent with the main step in the lowtemperature magnetization curves.

The experimental results can be also interpreted by assuming a single inter-ring parameter $J_{\mathrm{Ni}(\mathrm{p})-\mathrm{Ni}(\mathrm{g})}=J_{\mathrm{Ni}(\mathrm{p})-\mathrm{Cr}(\mathrm{g})}=$ $10-0.62 \mathrm{~K}$. This model allows us to simulate specific heat and EPR Q-band data with the same level of agreement of Figures 3 and 4 (inset). However, W-band results are better reproduced with the model discussed above.

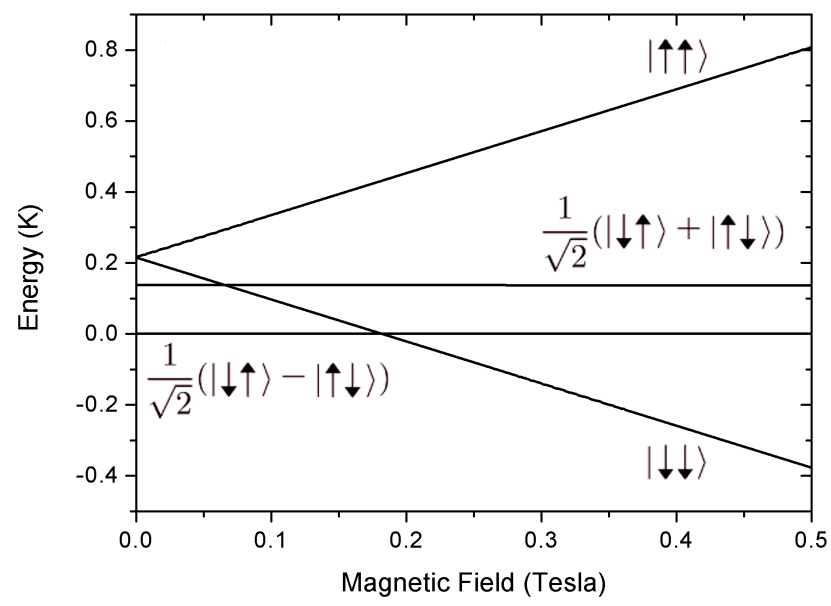

15 Figure 6. Calculated magnetic field dependence of the lowest lying energy levels of 7, with $\mathbf{B}$ perpendicular to the rings.

We now proceed with the evaluation of the magnetic coupling between the magnetic ions belonging to different rings 20 through the organic linker by DFT calculations. The results have been obtained employing the NWChem quantum chemistry package. ${ }^{11}$ In order to account for the electronic correlation, we used the B3LYP hybrid exchange-correlation functional. ${ }^{12}$ Broken-symmetry (BS) magnetic configurations 25 were obtained with the help of the constrained-DFT method. ${ }^{13,14}$

We follow the procedure described in reference 15, where total energies of different broken symmetry (BS) states are mapped onto a microscopic spin model Hamiltonian, 30 which contains only isotropic Heisenberg exchange terms (dipolar interactions are tiny and spin-orbit coupling is not included in the calculation). ${ }^{16}$ The problem can be further simplified, considering that intra-ring interactions are one order of magnitude larger than inter-ring interactions ${ }^{17-21}$ 35 which implies that excited states probed in low-temperature experiments are associated to variations of the total spin of the dimer, keeping frozen the molecular spins in each ring. If we consider BS states where the antiferromagnetic intra-ring coupling is maintained, total energies of the BS states could 40 be rewritten as

3)

$$
\begin{aligned}
E=E^{\text {intra }}+J_{\mathrm{Ni}(\mathrm{p})} & -\mathrm{Cr}(\mathrm{g}) s_{\mathrm{ZNi}(\mathrm{p})} \cdot s_{\mathrm{ZCr}(\mathrm{g})} \\
& +J_{\mathrm{Ni}(\mathrm{p})-\mathrm{Ni}(\mathrm{g})} S_{\mathrm{ZNi}(\mathrm{p})} \cdot s_{\mathrm{ZNi}(\mathrm{g})}
\end{aligned}
$$

where $E^{\text {intra }}$ is a constant energy term, $J_{\mathrm{S}}$ are inter-ring 45 exchange parameters, and the various $s_{\mathrm{z}}$ are the spin moments of the three frontier ions (see Figure 1). According to eq.3, if we retain the antiferromagnetic coupling between the spins in each of the ring, and flip coherently all the spins in one of the ring, we could obtain the total energies of only two BS 50 states, characterized by having the total spins of the two rings coupled either ferro- (FM) or antiferromagnetic (AFM) to each other.

Contrary to the purple-purple dimer case, ${ }^{15}$ we have here two unknown inter-ring exchange constants, $J_{\mathrm{Ni}(\mathrm{p})-\mathrm{Ni}(\mathrm{g})}$ and

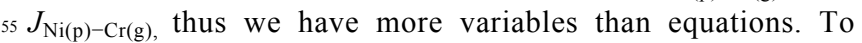
overcome this problem, we make the assumption that the two microscopic interactions $\mathrm{Ni}(\mathrm{p})-\mathrm{Ni}(\mathrm{g})$ and $\mathrm{Ni}(\mathrm{p})-\mathrm{Cr}(\mathrm{g})$ could be considered, in first approximation, independent from each other, i. e. if the $\mathrm{Ni}(\mathrm{g})$ is substituted with a different divalent ${ }_{60}$ ion, the interaction between $\mathrm{Ni}(\mathrm{p})$ and $\mathrm{Cr}(\mathrm{g})$ remains unaltered. Substituting the $\mathrm{Ni}$ on the green ring with a $\mathrm{Zn}(s=$ 0 ) non magnetic ion, we can thus turn off one of the interaction channel, and obtain the $\mathrm{Ni}(\mathrm{p})-\mathrm{Cr}(\mathrm{g})$ exchange constant. Once $J_{\mathrm{Ni}(\mathrm{p})-\mathrm{Cr}(\mathrm{g})}$ is calculated, we determine the ${ }_{65} J_{\mathrm{Ni}(\mathrm{p})-\mathrm{Ni}(\mathrm{g})}$ exchange coupling, from the FM and AFM BS states of complex 7. The total energy differences between AFM and FM states are respectively -2.1 and $-3.1 \mathrm{~K}$, showing that low spin states are energetically favored with respect to the high spin ones. This is in agreement with the experimental 70 finding that in complex 7 the magnetic ground state is a singlet. The inter-ring exchange parameters found are $J_{\mathrm{Ni}(\mathrm{p})-\mathrm{Cr}(\mathrm{g})}=-0.7 \mathrm{~K}$ and $\mathrm{J}_{\mathrm{Ni}(\mathrm{p})-\mathrm{Ni}(\mathrm{g})}=0.6 \mathrm{~K}$. Interestingly, they are not always antiferromagnetic $(J>0)$ as it happens in the purple-purple dimers ${ }^{15}$ but they can be ferromagnetic as well.

The above assumption of transferability of the microscopic exchange parameters from one derivative to another, although crude at first sight, is based on the widely-used reformulation of a multi-spin interaction problems into the sum of pairwise 80 spin-spin interactions; the applicability of this approach for very small interactions, as the one discussed above, is indeed a challenge for state-of-the-art DFT calculations and represents an issue worth to be analyzed further in multi-ion magnetic molecules. In order to get more insight on the 85 interaction channel we show in Fig. 7 three-dimensional contour plot of the spin polarization density, zooming in the interaction region across the nicotinate bridge. From the 
accurate analysis of the spin-polarized electron density in the carboxylate group belonging to the iso-nicotinate bridge in Figures 7 , a sort of competition emerges between the two metallic ions placed on the green ring of the dimer: the atom 5 with the largest absolute value of the spin imposes his own spin alternation along the iso -nicotinate bridge up to the first $\mathrm{C}$ atom of the pyridine ring. Such spin polarization must match the one across the pyridine ring, which in turn is determined by the sign of the spin moment of the divalent ion, 10 in this case $\mathrm{Ni}$, of the purple ring. ${ }^{15}$ In complex 7, the polarization induced on the nicotinate bridge due to $\operatorname{Cr}(\mathrm{g})$ overrides the one of $\mathrm{Ni}(\mathrm{g})$, this behavior being also reflected by the fact that $J_{\mathrm{Ni}(\mathrm{p})-\mathrm{Cr}(\mathrm{g})}$ is larger than $J_{\mathrm{Ni}(\mathrm{p})-\mathrm{Ni}(\mathrm{g})}$.

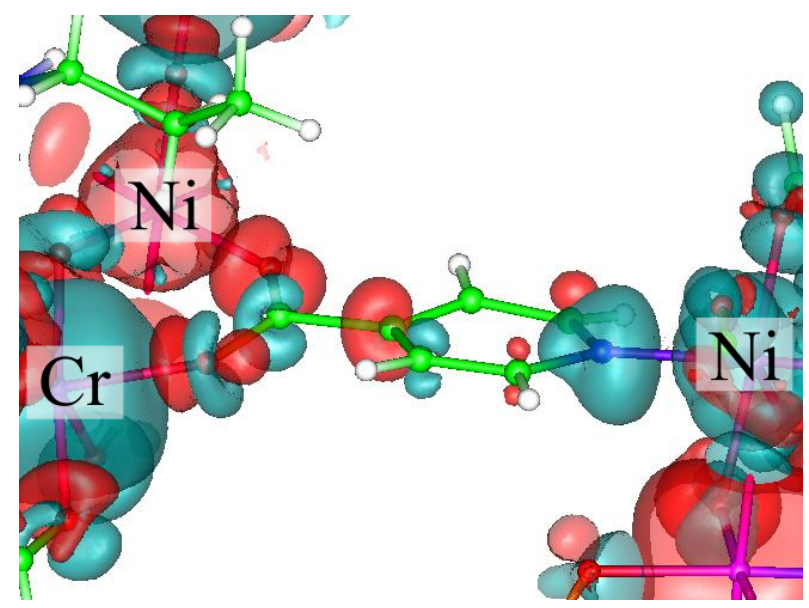

Figure 7 Spin-polarization density in complex 7 in the AFM configuration, zoomed in the region of the nicotinate bridge, for isovalues of + (cyan) and - (red) 0.0005 electrons/a.u.

${ }_{15}$ Summarizing, ab-initio DFT calculations point to two microscopic inter-ring exchange interactions having the same magnitude but opposite sign, an antiferromagnetic $\mathrm{Ni}-\mathrm{Ni}$ coupling and a ferromagnetic $\mathrm{Ni}-\mathrm{Cr}$ one. These results are therefore fully consistent with the miscroscopic spin 20 Hamiltonian used to interpret experimental results. The discrepancy in the magnitude of the exchange constants is within the uncertainty in the determination of the intermolecular exchange constants and consistent with what is typically found using the B3LYP functional to account for 25 electronic correlations. ${ }^{15,17}$

\section{Conclusion}

This family of supramolecular dimers composed of different heterometallic rings constitutes an important step toward the 30 use of this kind of systems for quantum information processing. Indeed, linking molecular qubits with different level schemes enables the implementation of important twoqubit gates like the CNOT gate, where the possibility of separately addressing the two qubits is mandatory. ${ }^{5,22,23}$ One 35 issue, which has been considered elsewhere ${ }^{24}$ is the magnitude of the exchange interaction and the resulting gate time; here the interaction is too strong to be able to manipulate single qubits without manipulating both; further synthetic work will increase the length of the space between the green and purple
40 rings. We also aim to introduce a switchable effective coupling between the molecular qubits by inclusion of a redox-active group between the rings. ${ }^{25}$

\section{Acknowledgments}

${ }_{45}$ We are grateful to the EPSRC (UK) for funding, especially of the National EPR Facility. M. Albring is a member of the EPSRC supported Centre for Doctoral Training NoWNANO. We acknowledge financial support also from the FIRB Project No. RBFR12RPD1 of the Italian Ministry of Education and ${ }_{50}$ Research. This work has been partially supported by EC through the FET-Proactive Project "MoQuaS", contract N.610449. We also acknowledge the CINECA center for granting the high-performance computing resources.

\section{Notes and references}

${ }_{55}{ }^{a}$ School of Chemistry and Photon Science Institute, The University of Manchester, Oxford Road. M13 9PL, Manchester (UK). Fax: (+44)161275-4616; E-mail: richard.winpenny@manchester.ac.uk

${ }^{b}$ Dipartimento di Scienze Fisiche, Informatiche e Matematiche.

Università di Modena e Reggio Emilia, via Campi 213/a, 41125 Modena, 60 Italy.

${ }^{c}$ CNR-NANO-S3 via Campi 213/a, 41100 Modena, Italy.

${ }^{\mathrm{d} D i p a r t i m e n t o ~ d i ~ F i s i c a ~ e ~ S c i e n z e ~ d e l l a ~ T e r r a, ~ U n i v e r s i t a ̀ ~ d i ~ P a r m a, ~}$

Parco Area delle Scienze 7/A, 43124 Parma, Italy

e. Laboratoire Louis Néel-CNRS, BP 166, 25 Avenue des Martyrs, 6538042 GRENOBLE Cedex 9, France

\$Current address: Instituto de Ciencia de Materiales de Aragón, Calle Pedro Cerbuna 12, 50009, Zaragoza, Spain.

$\dagger$ Electronic Supplementary Information (ESI) available: experimental details and selected bond lengths and angles for 1, 2, 3 and 5. See 70 DOI: $10.1039 / \mathrm{b} 000000 \mathrm{x} /$

1 (a) F. Troiani, A. Ghirri, M. Affronte, S. Carretta, P. Santini, G Amoretti, S. Piligkos, G. Timco and R. E. P. Winpenny, Phys. Rev. Lett. 2005, 94, 207208; (b) A. Ardavan, O. Rival, J. J. L. Morton, S. J. Blundell, A. M. Tyryshkin, G. A. Timco and R. E. P. Winpenny, Phys. Rev. Lett. 2007, 98, 057201.

2 (a) G. A. Timco, S. Carretta, F. Troiani, F. Tuna, R. G. Pritchard, E. J. L. McInnes, A. Ghirri, A. Candini, P. Santini, G. Amoretti, M. Affronte and R. E. P. Winpenny, Nature Nanotechnology, 2009, 4,

${ }_{80}$ 173; (b) G. F. S. Whitehead, F. Moro, G. A. Timco, W. Wernsdorfer, S. J. Teat and R. E. P. Winpenny, Angew. Chem. Int. Ed., 2013, 52, 9932.

3 E. Garlatti, M. A. Albring, M. L. Baker, R. J. Docherty, V. Garcia Sakai, H. Mutka, T. Guidi, G. F. S. Whitehead, R. G. Pritchard, G. A.

85 Timco, F. Tuna, G. Amoretti, S. Carretta, P. Santini, G. Lorusso, M. Affronte, E. J. L. McInnes, D. Collison and R. E. P. Winpenny, J. Amer. Chem. Soc., 2014, 136, 9763.

4 (a) A. Candini, G. Lorusso, F. Troiani, A. Ghirri, S. Carretta, P. Santini, G. Amoretti, C. Muryn, F. Tuna, G. Timco, E. J. L. McInnes, R. E. P. Winpenny, W. Wernsdorfer and M. Affronte, Phys. Rev. Lett. 2010, 104, 037203; (b) T. B. Faust, V. Bellini, A. Candini, S. Carretta, G. Lorusso, D. R. Allan, L. Carthy, D. Collison, R. J. Docherty, J. Kenyon, J. Machin, E. J. L. McInnes, C. A. Muryn, H. Nowell, R. G. Pritchard, S. J. Teat, G. A. Timco, F. Tuna, G. F. S. Whitehead, W. Wernsdorfer, M. Affronte and R. E. P. Winpenny, Chem. Eur. J. 2011, 17, 14020; (c) T. B. Faust, F. Tuna, G. A. Timco, M. Affronte, V. Bellini, W. Wernsdorfer and R. E. P. Winpenny, Dalton Trans., 2012, 41, 13626; (d) A. Fernandez, E. M. Pineda, C. A. Muryn, S. Sproules, F. Moro, G. A. Timco, E. J. L. 100 McInnes and R. E. P. Winpenny, Angew. Chem. Int. Ed., 2015, 54, 10858.

5 (a) Y. Morita, Y. Yakiyama, S. Nakazawa, T. Murata, T. Ise, D. Hashizume, D. Shiomi, K. Sato, M. Kitagawa, K. Nakasuji and T. Takui, J. Am. Chem. Soc. 2010, 132, 6944; (b) S. Nakazawa, S. Nishida, T. Ise, T. Yoshino, N. Mori, R. D. Rahimi, K. Sato, Y. 
Morita, K. Toyota, D. Shiomi, M. Kitagawa, H. Hara, P. Carl, P. Höfer and T. Takui, Angew. Chem. Int. Ed. 2012, 51, 9860.

6 (a) J. Lehmann, A. Gaita-Ariño, E. Coronado, D. Loss, D. Nat Nanotechnol. 2007, 2, 312; (b) M. Shiddiq, D. Komijani, Y. Duan, A. Gaita-Ariño, E. Coronado and S. Hill, S. Nature 2016, 531, 238; (c) J. P. S. Walsh, S. B. Meadows, A. Ghirri, F. Moro, M. Jennings, W. F. Smith, D. M. Graham, T. Kihara, H. Nojiri, I. Vitorica-Yrezabal, G. A. Timco, D. Collison, E. J. L. McInnes and R. E. P. Winpenny, Inorg. Chem., 2015, 54, 12019.

107 (a) M. Warner, S. Din, I. S. Tupitsyn, G. W. Morley, A. Stoneham, J. A. Gardener, Z. Wu, A. J. Fisher, S. Heutz, C. W. M. Kay and G. Aeppli, Nature 2013, 503, 504; (b) M. J. Graham, J. Zadrozny, M. Shiddiq, J. S. Anderson, M. S. Fataftah, S. Hill and D. E. Freedman, J. Am. Chem. Soc. 2014, 136, 7623. (c) K. Bader, D. Dengler, S.

15 Lenz, B. Endeward, S. -D. Jiang, P. Neugebauer and J. van Slageren, Nat. Commun. 2014, 5, 5304. (d) M. Atzori, L. Tesi, E. Morra, M. Chiesa, L. Sorace and R. Sessoli, J. Am. Chem. Soc. 2016, 138, 2154; (e) K. S. Pedersen, A. -M. Ariciu, S. McAdams, H. Weihe, J. Bendix, F. Tuna and S. Piligkos, J. Am. Chem. Soc. 2016, DOI: 10.1021/jacs.6b02702.

8 (a) E. J. L. McInnes, G. A. Timco, G. F. S. Whitehead and R. E. P. Winpenny, Angew. Chem. Int. Ed., 2015, 54, 14244 and refs. therein; (b) S. Piligkos, H. Weihe, E. Bill, F. Neese, H. El Mkami, G. M. Smith, D. Collison, G. Rajaraman, G. A. Timco, R. E. P. Winpenny

25 and E. J. L. McInnes, Chem. Eur. J. 2009, 15, 3152.

9 S.F. Lincoln, Helv. Chim. Acta, 2005, 88, 523.

10 V. Corradini, A. Ghirri, E. Garlatti, R. Biagi, V. De Renzi, U. del Pennino, V. Bellini, S. Carretta, P. Santini, G. Timco, R. E. P. Winpenny and M. Affronte, Adv. Funct. Mat., 2012, 22, 3706-3713.

3011 M. Valiev, E. J. Bylaska, N. Govind, K. Kowalski, T. P. Straatsma, H. J. J. Van Dam, D. Wang, J. Nieplocha, E. Apra, T. L. Windus and W. A. de Jong, Comp. Phys. Commun., 2010, 181, $1477-$ 1489 .

12 A. D. Becke, J. Chem. Phys., 1993, 98, 5648-5652.

3513 Q. Wu and T. Van Voorhis, Phys. Rev. A, 2005, 72, 024502.

14 I. Rudra, Q. Wu and T. Van Voorhis, J. Chem. Phys., 2006, 124, 024103 .

15 V. Bellini, G. Lorusso, A. Candini, W. Wernsdorfer, T. B. Faust, G. A. Timco, R. E. P. Winpenny and M. Affronte, Phys. Rev. Lett., 2011, 106, 22720

16 S. J. Blundell, Magnetism in Condensed Matter. Oxford University Press, 2001.

17 (a) V. Bellini and M. Affronte, J. Phys. Chem. B, 2010, 114, 1479714806; (b) M. L. Baker, S. Piligkos, A. Bianchi, S. Carretta, D

45 Collison, J. J. W. McDouall, E. J. L. McInnes, H. Mutka, G. A Timco, F. Tuna, P. Vadivelu, H. Weihe, H. U. Güdel and R. E. P. Winpenny, Dalton Trans., 2011, 40,8533.

18 R. Caciuffo, T. Guidi, G. Amoretti, S. Carretta, E. Liviotti, P. Santini, C. Mondelli, G. Timco, C. A. Muryn, and R. E. P. Winpenny, Phys. Rev. B, 2005, 71, 174407.

19 M. Allalen and J. Schnack, J. Magn. Magn. Materials, 2006, 302, 206-210.

20 H. Amiri, M. Mariani, A. Lascialfari, F. Borsa, G. A. Timco, F. Tuna and R. E. P. Winpenny, Phys. Rev. B, 2010, 81, 104408.

5521 L. Engelhardt, C. Muryn, R. Pritchard, G. Timco, F. Tuna and R. E. P. Winpenny, Angew. Chem. Int. Ed., 2008, 47, 924-927.

22 F. Luis, A. Repollés, M. J. Martìnez-Pérez, D. Aguilà, O. Roubeau, D. Zueco, P. J. Alonso, M. Evangelisti, A. Camòn, J. Sesé, L. A Barrios, and G. Aromì, " Phys Rev Lett, 2011, 107, 117203.

6023 D. Aguilà, L. A. Barrios, V. Velasco, O. Roubeau, A. Repollés, P. J. Alonso, J. Sesé, S. J. Teat, F. Luis, and G. Aromí, J. Am. Chem. Soc., 2014, 136, 14215-14222.

24 A. Ardavan, A. Bowen, A. Fernandez, A. Fielding, D. Kaminski, F. Moro, C. A. Muryn, M. Wise, A. Ruggi, E. J. L. McInnes, K

65 Severin, G. A. Timco, C. Timmel, F. Tuna, G. F. S. Whitehead and R. E. P. Winpenny, NPJ Quantum Information, 2015, 1, 15012.

25 J. Ferrando-Soria, E. M. Pineda, A. Chiesa, A. Fernandez, S. Magee, S. Carretta, P. Santini, I. Vitorica-Yrzebal, F. Tuna, G. A. Timco, E. J. L. McInnes and R. E. P. Winpenny, Nat. Commun., 2016, 7, 11377. 